\title{
Emotional Control Scale
}

National Cancer Institute

\section{Source}

National Cancer Institute. Emotional Control Scale. NCI Thesaurus. Code C121465.

A rating scale included in the Behavior Rating Inventory of Executive Function that measures the ability of an individual to regulate emotional responses appropriately. 